\title{
INNOVATION: THE ENDLESS TRANSITION
}

Henry Etzkowitz ${ }^{1}$

\begin{abstract}
Innovation is increasingly based upon a "Triple Helix" of university-industry-government interactions, which modifies the role of each institutional sphere. As the university takes on a new role in promoting innovation, it becomes transformed into an economic institution, while retaining its traditional missions. As firms take their new role in continually adapting and raising their technological level, they move a closer to an academic model. As government plays a role as public entrepreneur it becomes more like the industrial and academic spheres in realizing the importance of knowledge in creating a new economy and new society. Moving beyond 'learning' and adaptation, development then becomes an endogenous process of encouraging linkages among the institutional spheres to foster innovation.
\end{abstract}

\section{Introduction}

The university has traditionally been viewed as a support structure for innovation, providing trained persons, research results and knowledge to firms while innovation has been viewed as a phenomenon of the private sector. The transformation of academia is reflected in the evolution of innovation itself from an internal process within firms to an interface among firms and with knowledge-producing institutions such as universities and government laboratories. As the production of scientific knowledge has been transformed into an economic enterprise; the economy has also been transformed since it increasingly operates on an epistemological base. ${ }^{i}$ Intellectual property is becoming as important as financial capital as the basis of future economic growth, indicated by the inadequacy of traditional models of valuing firms primarily in terms of their tangible assets.

In some countries, there is a movement away from an assumption that there is single starting point of research and an end point of the economy: a linear model in which things happen by themselves. It is also realized that it is necessary to start from the standpoint of problems in society, the reverse linear model, and seeing how knowledge can be used to address them. ${ }^{\text {ii }}$ It is increasingly the case that industrial firms need the application of knowledge to improve their production processes or to

${ }^{1}$ Science Policy Institute, State University of New York at Purchase 
develop new firms on the basis of knowledge. It cannot be expected that entrepreneurs can always do this by themselves. Government programs have an important role to play, not only from the national level -top down-but also from the local level-bottom-up, often in collaboration with other organizations in civil society

The Triple Helix model of simultaneously competing and cooperating institutional spheres differs from situations in which the state encompasses industry and the university, for example, the former Soviet Union, and some European and Latin American countries, in the era when state owned industries were predominant. It is also different from separate institutional spheres, for example, how the US is supposed to work, at least in theory, as a "laissez-faire" society. From either of these starting points, there is a movement toward a new global model for the management of knowledge and technology that enables analysis of the dynamics of innovation in terms of historical trends, new structural arrangements, and emerging moments of change.

\section{EMERGENCE OF THE TRIPLE HELIX}

Society is more complex than biology. A "double helix" was sufficient to model DNA. A "triple helix" is required to model university-industry- government interactions.

The Triple Helix thesis is expressed in eight propositions:

1. Arrangements and networks among the Triple Helix institutional spheres provide the source of innovation rather than any single driver. New initiatives arising from these networks become the source of innovation policies at national, subnational, and supranational levels. Innovation is a broader phenomenon than anything that takes place in a single institutional sphere such as the behavior of enterprises in planning and implementing changes to develop new products or learning from fellow firms in a cluster or other sector. Academic research now increasingly intersects with industrial advance and government economic development policy. Government thus becomes a partner in the policy-making process as policies become an outcome of the interactions among the Triple Helix agencies.

2. Invention of new social arrangements becomes as important as the creation of physical devices. New organizational mechanisms such as incubators, science parks, and networks among them become a source of economic activity, community formation, and international exchange. New modes of interdisciplinary knowledge production, involving Triple Helix partners, translate into firm formation at the Internet and business incubation in various settings.

\section{New channels for interaction link the various institutional spheres and speed the pace of innovation. \\ The linear model of transfer of knowledge generated in academia is supplemented with the transfer of technology both as intellectual property and through the formation of firms by alumni and staff. The reverse linear model starting from industrial and social problems provides starting points for new research programs and discipline formation. The interaction between these two dynamics results in the emergence of an interactive mode of innovation.}

4. Capital-formation takes on new aspects even as new forms of capital are created. The transformation of capital cannot be fully understood from the perspective of either the individual firm or the operation of markets. New forms of capital are created based upon social interaction, "who you know," and intellectual activities, "what you know." Forms of capitals are interchangeable. Thus, raising financial capital is based on accumulating intellectual as well as 
social capital. Human, social, and intellectual capital needs are redefined as firms relate to universities and government.

5. Globalization becomes decentralized and takes place through networks among universities as well as through multi-national corporations and international organizations. As organizational innovations for technology transfer diffuse from one part of the world to another, interaction across regions and nations reinforces globalization. As universities develop links, they can combine discrete pieces of intellectual property and jointly exploit them. These new configurations become the basis of a continuous process of firm formation, diversification, and collaborations among competitors.

6. Developing countries and regions have the possibility of making rapid progress insofar as knowledge sources can be absorbed into the political economy. Political and social arrangements based upon principles of equity and transparency lay the groundwork for rapid development in a stable environment. "Leapfrogging," to skip some stages of development, is thus more likely. Universities and networked incubators can be utilized both to adapt advanced technologies to solve local problems as well as to transfer local innovations abroad.

7. Reorganizations across institutional spheres, industrial sectors and nation states are induced by opportunities in new technologies. Technological innovation reshapes the landscape in terms of the development of niches and clusters, relations among firms of different sizes and types and the creation of both public and private sources of venture capital. Enterprises are constructed out of elements from all the relevant institutional spheres, not just from industry itself. Social developments take unexpected turns as new technologies reinforce the dynamics of firm formation and vice versa.

8. Universities increasingly become the source of regional economic development and academic institutions are re-oriented or founded for this purpose.

The growth of industrial conurbations around universities, supported by overnment research funding, has become the hallmark of an entrepreneurial development model, exemplified by Silicon Valley; the profile of knowledge-based economic development was further raised by the founding of Genentech and other biotechnology companies by academics and venture capitalists in the 1980s. Other regions in other countries such as Karlskronna Ronneby in Sweden and the State University of Rio de Janeiro in Friburgo have adapted this strategy to revive declining industrial regions or develop "greenfield" sites such as the State University of New York at Stony Brook.

\section{INNOVATION IN INNOVATION}

Institution-formation and incubation of new enterprises involves the creation of knowledge, consensus and innovation spaces along a non-linear continuum. A consensus space can bring the different actors in a region or country together. From the analysis of the resources in a region an awareness can be generated of the potential of its knowledge space that, in turn, can became the basis for the creation of an innovation space. These "development spaces" can theoretically be created in any order, with any one of them used as the basis for the development of others.

\section{KNOWLEDGE SPACE}

The concept of "knowledge space" was developed by Dr. Rosalba Casas at UNAM as a way of conceptualizing movement of a number of research institutes from Mexico City to regions of Mexico. ${ }^{\text {iii }}$ This decentralization of research provided a base for the new technology related businesses in areas of the society, which had not previously had this potential. Some of this decentralization took place due to an earthquake. Other relocation occurred because it was decided that it was best not to concentrate technical resources in one place. Nevertheless, just as the existence of research universities by the 1920's and 30's in the US represented a potential for 
knowledge-based economic development, similarly these research institutes in other parts of Mexico still only represent a potential until they are put to use.

\section{CONSENSUS SPACE}

A consensus space provides a neutral ground to gain acceptability and support to introduce new ideas for economic and social development. The Honduran organization, FONEC, for example, represents such a consensus space where groups and individuals from various parts of society (e.g. business, labor, indigenous peoples) meet together to discuss issues and solve problems. A meeting in July, 2000, called by the Minister of Science and Technology, heard presentations and discussed the applicability of the incubator concept. Another example of a consensus space was an organization created in the New England states in the 1920's and 30's. The New England Council brought together leaders of university, industry and government to discuss the problems of a region which had been in a depression since the turn of the century when its industries had left to move to other parts of the country. After thinking about all of the existing ideas for economic development which were typically to reduce taxes or to subsidize businesses, it was concluded that these strategies were unworkable. New England was too far from sources of raw materials and distribution distances were too great.

\section{INNOVATION SPACE}

President Compton of MIT convinced the Council members that that the region special resource were its universities, especially in the Boston area, Harvard and MIT and examples of new firms that had been started from universities. The venture capital firm was invented, just after the $2^{\text {nd }}$ World War to provide missing elements in the ability of the region to create new companies. Technology was available in Universities such as MIT and Harvard but potential entrepreneurs needed financial and business assistance to create companies. American Research and Development Inc. (ARD) was organized to provide financing, business and technical advice to entrepreneurs. The venture capital firms served as a proto-incubator and some of the firms located in underutilized spaces on the MIT campus. ${ }^{\text {iv }}$

From these experiences we can infer the importance of analyzing a particular situation to determine:

1. the local resources that can be used to start the incubation process;

2. What is missing and how and where those missing resources can be found, either locally or internationally.

To arrive at such a collaboration means that there has to be discussions among the potential actors rather than government saying this is what should be done by itself.

\begin{tabular}{|l|l|}
\hline \multicolumn{1}{|c|}{ Facilitating Conditions for Knowledge-Based Economic Development } \\
\hline \multicolumn{1}{|c|}{ Stage of development } & \multicolumn{1}{c|}{ Characteristics } \\
\hline Creation of a knowledge space & $\begin{array}{l}\text { Focus on "regional innovation environments" where different actors work to } \\
\text { improve local conditions for innovation by concentrating related R\&D } \\
\text { activities and other relevant operations }\end{array}$ \\
\hline Creation of a consensus space & $\begin{array}{l}\text { Ideas and strategies are generated in a "triple helix" of multiple reciprocal } \\
\text { relationships among institutional sectors (academic, public, private) }\end{array}$ \\
\hline
\end{tabular}




\section{Chart 2.}

\section{FROM INDIVIDUAL TO COLLECTIVE ENTREPRENEURSHIP}

The transition from one space to another typically occurs through entrepreneurial initiatives. I have identified several types of "preneurships" defined as the uniting of several types of capital, social, intellectual and financial within and among organizations as well as in the creation of new organizations. Preneurship involves the projection of a future vision, the mean to realize it and the convincing people and groups to take specific steps to achieve the goal. Individual entrepreneurs are complemented by organizational entrepreneurs, such as the U.S. Department of Agriculture, recognized by Schumpeter, ${ }^{v}$ and the emergence of entrepreneurial activities at the boundaries of the institutional spheres such as the New England Council.

In countries with a laissez faire tradition, such as the U.S. , the role of government and academia in the generation of Route 128, Silicon Austin, Texas and the Research Triangle has been obscured by an individualistic ideology that credits only individual entrepreneurs and venture capitalists.

\section{Typology of Organizational Innovation}

\begin{tabular}{|c|l|}
\hline Preneurships: & \multicolumn{1}{c|}{ Bring together resources: } \\
\hline Intra-preneurship & for a new project within an existing organization \\
\hline Entrepreneurship & $\begin{array}{l}\text { from diverse sources e.g. social, intellectual and } \\
\text { financial capitals to establish a new organization }\end{array}$ \\
\hline Inter-preneurship & $\begin{array}{l}\text { from different organizations in the same institutional } \\
\text { sphere to establish a joint project }\end{array}$ \\
\hline Extra-preneurship & $\begin{array}{l}\text { from different institutional spheres to establish a venue } \\
\text { for collaboration. }\end{array}$ \\
\hline
\end{tabular}

Chart 3.

\section{REGIONAL DEVELOPMENT IN THE KNOWLEDGE SOCIETY}

As entrepreneurial academic activities intensify, they may ignite a self-generating process of firmformation, no longer directly tied to a particular university. The growth of industrial conurbations around universities, supported by government research funding, has become the hallmark of a regional innovation system, exemplified by Silicon Valley; the profile of knowledge-based 
economic development was further raised by the founding of Genentech and other biotechnology companies based on academic research in the 1980s. Once takeoff occurs in the U.S. only the private sector is usually credited; the role of government, for example, the Defense Research Projects Agency (DARPA) in founding SUN, Silicon Graphics and Cisco is forgotten. ${ }^{\text {vi }}$

Most regions, however, lack innovation systems; rather they are innovation environments with some elements to encourage innovation present and others missing. In such situations it is important for some group or organization to play the role of regional innovation organizer (RIO) and bring the various elements of the triple helix together to foster new projects. Things start to grow around concepts, like Silicon Alley in New York and Oresund in Copenhagen/southern Sweden, that unite politicians, businesspersons and academics. Imagery is also important since there often are not strong market reasons to allocate resources to development of a region. ${ }^{\text {vii }}$

In the early 1980's a half dozen US states had technology agencies; at present every state has some type of program . Over time there has been a shift in the role of these agencies. Upon their founding they primarily supported academic research with commercial potential, often as a supplement to projects supported by federal basic and applied research funding programs.

Over time, many states have shifted their focus away from academia and used their resources to assist development of new companies and improve the production processes and products of older firms. This policy was relatively uncontroversial, given the traditional role of local and state governments in economic development. The role of the national government in civilian technology development has been much more controversial. Some critics view such intervention as an attack on the market, an inappropriate interference that is doomed to failure.

\section{TRANSITION IN A MARKET ECONOMY}

There are two types of transition: one is in the laws and regulations provided by a governmental infrastructure; the other is the institutions themselves and their relationships to each other. In the former socialist countries the rules and regulations of a central planning system are discarded in favor of market mechanisms. However, the relationship of state to market is often misunderstood.

The existence of a market does not imply the absence of formal governmental involvement in economic life. Indeed, the market is a creature of the state. It is an institutional sphere with rules and regulations established under governmental aegis to guarantee secure contracts, recognizable to all parties, with modes of redress in the event of disputes or failure to meet agreed upon obligations.

Most fundamentally, at least in theory, the market allows free non-coerced transactions to take place. However, the existence of a market, by itself, does not insure a well functioning system of technological innovation and economic growth. This can be seen in the recent experience of the United States where market mechanisms have been supplemented by a series of government actions to improve the functioning of the industrial and innovation systems.

In the past two decades, in fits and starts, sometimes as hidden policy and, more recently, as open policy, government has played a larger role in industry, through policies and programs, but also by changing the rules of the game. One fundamental rule of the United States economy, established by law in the late $19^{\text {th }}$ century, has been that corporations should not collaborate with each other. 
Anti-trust rules that inhibit collaboration among firms have largely been eliminated in the past two decades. Laws prohibiting monopolization are still in place and they continue to influence large companies to not entirely eliminate competitors. During the 1960 's, a major anti-trust case was brought against the IBM Corporation. Indeed, until quite recently the company operated under a court decree, giving a judge authority over some actions of the company even though the threat of monopolization has long since past. In the case of Microsoft, a break-up if it takes place will leave the industry as an oligopoly.

Much more significant than the relatively unusual prosecution of dominant firms to encourage competition is that the rules prohibiting firms working together have been changed in order to encourage cooperation. Joint ventures, consortia of companies to produce and market products together are now legal and R\&D consortia are, at times, even subsidized.

Why were the rules of the game revised? There was no collapse of the political system as in Eastern Europe. Nor can an ideological shift be the explanation since the weight of opinion continues to be in the opposite direction. Rather, the impetus to change was a partial collapse of the economy.

From the 70's to the early 80 's, heavy industrial sectors and mass production industries in the United States were under great strain from increased international competition. The effects of the crisis were summed up at the time in the term "rust belt," a mid-western region of declining metalworking and auto industries. Steel production, for example, disappeared from Pittsburgh, leaving not a single mill in a city that was internationally famous for this industry.

Nevertheless, heavy industry still makes up 50\% of employment in Pittsburgh but the other half consists of jobs created in software and medical devices firms. These have grown from several sources: area academic institutions such as Carnegie Mellon University and the University of Pittsburgh, from the closure of large corporate laboratories.

New firms have also emerged as second order spin-off's from the initial wave of companies that came out of area universities and firms. A significant number of these emerging firms received support from the Ben Franklin Program, the Pennsylvania State S\&T Agency with three regional sites including one in Pittsburgh.

\section{REFORMING THE NATIONAL LABORATORIES}

In addition to Schumpeter's thesis of "creative destruction" there are also processes of "creative renewal" finding new functions for old institutions. This can especially be seen in the changing role of the national laboratories, especially those created during World War II. The most well known ones were set up to develop the atomic bomb project but there more than 600 laboratories established for a variety of purposes ranging from agriculture to health etc. In the late 1980's the laws governing these laboratories were changed to allow them to enter into agreements with companies to undertake cooperative research projects. 
By connecting a group of these companies to a national laboratory with relevant research capacities, even through they had never previously been applied to such problems, production processes and products were analyzed and improvements made. This process occurred in a variety of traditional industrial sectors such as the glass industry which also organized itself to form a research collective funded by the companies themselves that then took advantage of an NSF program to become part of a university center. Thus, through a program in which the government and companies jointly funded a research center, the industry gained an $R \& D$ capacity not previously available to it.

The national laboratories are aware that their future possibilities are far from the locus of the nuclear industry. Although, the Galvin Commission discouraged involvement with industry, it did not eliminate it. Nor did the report lead to the repeal of the laws that established the framework and funding for government-industry relations in the late 1980's. Although the national laboratories did not maintain the high rate of increase in projects with industry of the late 80's and early 90's, their interaction with industry persists.

The United States has developed a system of public venture capital consisting of a variety of federal and state programs that help make the "linear model" work by moving technology from the laboratory to the market. Even as the United States has taken a more activist role in S\&T policy, other countries, where government was dominant, have reduced its role. A convergence toward an "endless transition" of organizational innovation in university-industry- government relations, the "triple helix," is expected, rather than a fixed laissez faire endpoint. The result is an interactive model, with intermediate mechanisms, that integrate the two traditional starting points of science and technology policy.

In contrast to biological evolution, which arises from mutations and natural selection, social evolution occurs through 'institution formation' and conscious intervention. The triple helix provides a flexible framework to guide our efforts, from different starting points to achieve the common goal of knowledge-based economic and social development. Innovation thus becomes an Endless Transition, a self-organizing process of initiatives among the institutional spheres. The university plays a special role in the triple helix of innovation as a self-renewing organization through its inflow and outflow of students

\section{INDIRECT INDUSTRIAL POLICY}

The university is a flexible and capacious organization. Like the Church, its medieval counterpart, it is capable of reconciling apparent contradictions while pursuing multiple goals in tandem. As the university takes up a new role in promoting innovation, its educational and research missions are also transformed. As the university expands its role in the economy, from a provider of human resources to a generator of economic activity, its relationship to industry and government is enhanced.

Paradoxically, as the university becomes more influential in society; it is also more subject to influence, with academic autonomy increased in some instances and reduced in others. When bottom -up initiatives that have proved successful, such as the incubator movement in Brazil, are reinforced by top down policies and programs, perhaps the most dynamic and fruitful result is achieved. ${ }^{\text {viii }}$ It also means that universities and other knowledge producing institutions play a new role in society, not only in training students and conducting research but also in making efforts to see that knowledge is put to use. 
There were a very few universities such as MIT, from the late $19^{\text {th }}$ century and Stanford, during the post-war era, which developed close connections to industry. Most universities played the traditional role of providing trained persons and research findings through publications that would be available to industry, with perhaps some consulting relationships. As a side effect of a debate over whether government should play a more direct role in civilian technological innovation, a modest step was taken toward industrial policy.

The Bayh-Dole Act of 1980 encouraged universities to play an increased role in the economy by taking on a new role in technology transfer. The law required universities to make an effort to put research results to use as a condition of receiving government funds and granted ownership of the intellectual property rights emanating from federally funded research to the universities.

The premise of this change was that the billions of dollars of research funds supplied to the universities contained significant unrealized potential for technology development. Certainly, a government that did not believe it should directly assist industry to improve its innovation capabilities was hardly going to develop these intellectual property rights itself. Therefore, they would continue to remain underutilized. Procedures existed for a company to gain access to these rights. However, they were seldom used.

Companies felt that if they arranged to use this intellectual property, and were successful in developing a marketable product, a competitor would likely want to develop a similar product. The expectation was that a claim would be made that since the invention of the underlying technology had been supported by government, by the public's tax monies in fact, then the second company should be granted access to the technology, as well. Making this analysis in advance, the first company would then typically decide not to get involved---a classic free-rider effect.

In addition to encouraging the creation within universities of offices to license and market intellectual property, the change in laws also encouraged the expansion of a trend toward firmformation form academia, heretofore limited to a few specialized institutions such as MIT and Stanford. Some of these firms were formed to take advantage of emerging commercial opportunities in biotechnology, electronics and computer software. Others were inspired by the academic depression that, from the late 1970's, limited the appointment of new permanent staff.

Whether in the U.S. Eastern Europe or FSU, researchers worked for many decades under conditions of virtually guaranteed support. In a crisis situation, some have had to seek other employment opportunities. One solution is to translate capacities from these previous research sites into a marketable product within a new firm.

In the United States the transition from academia was aided by the entrepreneurial experience gained within the academic research funding system. Research groups have traditionally operated as quasi-firms within the universities, with professors responsible for raising their own funds for research. Many of these academic entrepreneurs have maintained their academic positions in U.S. universities, taking a leave to form a new firm and returning to academia whether the firm succeeded or failed. 
There is the beginning of an industrial sector appearing as a penumbra around many universities. Indeed, this phenomenon can be seen in many other parts of the world. For example, in Budapest, on Kende Street near the Technical University, there are several computer and software firms that were founded in the late 80's and early 90's from the University and the Institute sector. By the late 1980 's the indirect strategy of utilizing the universities to further economic development and the decentralized programs at the state level began to be supplemented by direct federal initiatives in the United States.

\section{DIRECT INDUSTRIAL POLICY}

During the post-war era, the large sums of money spent by the U.S. on technology development, primarily for military and health purposes, also produced significant spillovers in the economy in areas such as biotechnology and software. With the end of the Cold War, military expenditures for R\&D were expected to decline.

Moreover, despite indirect measures to assist industry, there was great concern in the mid-80's about the Japanese overtaking the U.S. in semi-conductors, and perhaps other technological areas. In response, the semi-conductor industry proposed an initiative for a joint industry-government funded R\&D support structure for the industry, SEMATECH. Although it ran counter to his stated beliefs, President Reagan supported this measure after he was assured by industry that it was a necessary measure to insure survival of the industry.

A broader initiative, to establish a civilian Advanced Technology Program on the model of the Defense Advanced Research Projects Agency (DARPA) occurred In the late 80s, during the Bush administration, against the opposition of the President. The Democrats who then held a majority in the Congress, initiated a modest program funded at the level of 15-20 million to provide grants of funds to individual firms and consortia of companies to develop pre-competitive or enabling technologies.

The program was formulated to meet objections to government funding product development in companies or duplicating the tasks of an agency such as NSF, mandated to support basic research. The objective was to define an intermediate space for action based upon the premise of "market failure," the increasing unwillingness of companies to conduct long-term R\&D.. Firms that could formerly take such a long term perspective due to lack of national or international competition, had to withdraw due to change in their status as regulated monopolies e.g. AT\&T or severe competition from new firms e.g. IBM.

The Advanced Technology Program (ATP) allows a firm, or consortia of firms, to develop a technology that is 2-3 years away from the market that is where the gap is between basic research and product development. Critics label the ATP and other similar programs that provide funds to companies to work on "enabling" or "pre-competitive technologies "corporate welfare."

Justifying the existence of an intermediary innovation space is no easy task. If a project is highly successful and gets to the market in a short time frame then it can be said that government intervened too close to product development, the responsibility of industry. On the other hand, if utility is found to be distant or non-existent, then the project will be judged to have more properly been in the purview of basic research agency such as NSF. 
After much controversy, the ATP program has shifted its funding strategy from supporting consortia led by large companies, who can afford to support the development of enabling technologies themselves if they wish. There is tighter focus on supporting smaller firms, either helping firms with research capacities move close to the market or helping firms that are close to the market acquire research capabilities so that they then engage in longer range technological development than a small firm normally can afford to undertake.

Even small high tech firms usually stay quite close to existing technologies. They may be at the edge of the technological frontier but rarely much beyond it. They will tell you that they cant afford to be long range, they have to be within a few months of reaching the market.

As the ATP moves in the direction of increasing its support of small firms, the ideological and political attacks that it has suffered will likely decline. Since small business has virtually sacred political status in the U.S., a role for the federal government in industrial technology development becomes more acceptable through this format.

This is one reason why the Small Business Innovation Research (SBIR) program, a "tax" on the research budget of all federal government agencies engaged in research to provide a staged series of grants to small companies to translate research into useful products has proved so popular with legislators.

\section{PUBLIC VENTURE CAPITAL}

Public venture capital plays an increasingly significant role in civilian innovation policy, contrary to expectations of a severely limited role for government in United States. The United States government has enlarged its role in S\&T policy, through laws enacted during the 1980's to encourage universities and national laboratories to engage in technology transfer. In addition to this indirect industrial policy, government programs have been established during the past decade to directly support civilian technological innovation, making public venture capital available, especially in niche priority areas.

Government is playing a key role in the United States transition, both at the macro and microeconomic levels. ${ }^{\text {ix }}$ Having abandoned central planning, some Eastern European countries took a laissez faire stance and severely limited their role in S\&T policy. On the other hand, western countries in which government traditionally played a quite limited role in innovation are moving closer to the former socialist system. Some are adopting a variant of the branch science model, in the form of networked research centers located at universities, but with the important difference of a lack of centralized controls.

Other parts of the world are moving in a similar direction to Eastern Europe, reducing the role of government in their economies. In Latin America, where governments played a predominant role in organizing industrial R\&D, changes are occurring similar to those in Eastern Europe and the Former Soviet Union. The various transitions, moving from either direction of high or low involvement suggests that there is an important, but not controlling, role for the state in technological innovation. 
For example, over the past half-century the US federal government has developed a series of programs to assist technology entrepreneurs, either in start-ups or innovative established firms. Government's objective is to generate jobs for future economic growth. Firms do not have to give up equity and in most instances retain their intellectual property rights.

The federal government gave out $\$ 1.2$ billion in FY 1999 in R\&D funds targeted directly at small firms through its Small Business Innovation Research Program (SBIR). An additional \$250 million in pre-competitive research funds was available through the Advanced Technology Program (ATP).

Started at NSF in 1977, the SBIR concept has spread to all agencies with research budgets over a certain amount. Over time, Congress has increased the percentage allocated for the SBIR from $1 / 2 \%$ to $2.5 \%$ The amounts given out are usually in the 50 to 150 thousand range for first stage grants to prove the feasibility of technology. A second stage grant in the 250 to 750 thousand range is for the development of a prototype.

A third stage of investment, taking the product to market, is expected to take place in the private sector. It is at this point that a gap has appeared, the so-called "Valley of Death." Many technologies that have emerged through the SBIR process were too far from the market to attract private investment.

Indeed, the first Bush administration contemplated closing down the SBIR when it realized that Japanese companies, with a longer term perspective than their U.S. counterparts were using the SBIR as a qualifying mechanism for making investments.

Although the program was continued, with many successful firms emerging from the process, much of the gap has persisted. One possibility is that the ATP, with its larger scale grants of 2 million for small firms, will fill some of this empty space in the U.S. innovation system.

The Small Business Administration (SBA) guarantees several billions in loans to small firms each year, although technology firms have problems in accessing these funds. Through the Manufacturing Extension Partnership (MEP), government provides funding for subsidized consulting services to small businesses, delivered through regional and local offices.

The Cooperative Research and Development Agreements (CRADAS) potentially offer approximately 700 government laboratories as partners on R\&D projects to which government can make in-kind contributions of researchers time and equipment. However, 70 laboratories actually undertake most of the partnerships.

There are also various programs, primarily in the Department of Defense (DOD), such as Act II and Mantech, that provide other funding opportunities to take completed R\&D work the next step toward production. The National Science Foundation (NSF) currently has an experimental program SBIR $2 \mathrm{~b}$, that provides matching funds, 2 parts private to one party government (current maximum is $\$ 100,000$ ), for successful Phase 2 awardees who qualify. Dual use programs in various $R \& D$ agencies in the DOD offer opportunities to demonstrate the usefulness of civilian technologies to the military and vice versa. 
Although the Federal government has made funds available at the very early stages of commercializing a technology, taking a technology from a successful prototype through production and finally to market is a persisting problem. State governments have acted to fill this gap in recent years, making available $\$ 3$ billion in funds in a variety of programs, typically oriented to the state's existing and projected industries.

Nevertheless, the gap remains large and federal government, venture capital industry and joint public-private initiatives like SBA loans have yet to address many of the issues facing technology entrepreneurs and innovative firms. For example, SBA loan guarantees have difficulties in taking into account the requirements of technology-based firms whose assets are typically in intellectual property rather than in fixed assets or inventory that can be used as collateral.

\section{THE ENDLESS TRANSITION}

Despite gaps, public venture capital makes it possible for the "linear model" based upon government $R \& D$ funding to achieve its stated goals of contributing to economic and social development, as outlined in the early post-war "Endless Frontier" Report [5]. The United States transition is one to a closer relationship of science to technology, of universities to industry and government and industry.

It is a transition to an increased role for government, in the opposite direction from Eastern Europe and Latin America, where there is reduced role for the state. Brazil, for example, has retreated from a leading role in technology policy, in part due to shrinking resources, but more importantly the failure of large scale government $R \& D$ programs to create entirely new technological sectors such as a national computer industry.

Many countries are currently attempting to follow a model represented by the United States, assuming it is one based on private venture capital. The significant role that "public venture capital" plays as the basis for much technological innovation that is taken the next step to the market by "start-up" firms is often forgotten. At minimum, the U.S. model certainly should not be adopted without realizing the significant role that government plays as well as taking into account local and regional circumstances and previous institutional heritages.

To emulate the United States model, one should be aware of what it actually consists rather than basing policy on an outdated laissez-faire scheme that, while still influential in theory, no longer accurately represents how the innovation system works in practice. Although its implementers cannot state that the United States has a civilian industrial policy, due to the ideological controversy that such an announcement would create, one is certainly in place as an accretion of programs, policies and institutional restructuring.

A common future is emerging in both developing and developed countries of a balanced innovation system, consisting of firms with R\&D units, research groups in universities and government Institutes and intermediary technology transfer and Fraunhofer type organizations. To take account of these new institutional roles and relationships is one reason for the development of a "triple helix" model. 
It also entails a research program to examine the emergence of networks and hybrid organizations that appear through intersections of university, industry and government. Incubator facilities that foster the development of high-tech start-ups, typically through a combination of public and private resources, represent an instantiation of the triple helix of university-industry-government relations [6].

The important methodological principle to note here is to take a very early look at changes that are taking place. It could be said that many of these organizational innovations, such as incubators, are very small in comparison to what some of these massive organizations such as the national laboratories are currently doing and what they have accomplished in the past.

Looking at a very few examples of science-based industry in the mid- $19^{\text {th }}$ century, Marx predicted that this would be the future of industrial development. Similarly, we must look at these very small changes in contemporary innovation systems and see what we can extrapolate from them. Finally, rather than a transition to an assumed fixed point, such as a market economy in the East, we may be in a state of continuous transition. Rather than an end state as in the assumption of a transition to market, it is more likely given the dynamic, competitive nature of technology development in a global economy that there will be the continuous invention of new roles and relationships for formerly static institutions.

Certainly the transition is not to a pure market since no country is giving up subsidies entirely and some are creating new ones. Rather the transition is toward a mixed system of market forces and government incentives. East/West, North/South: the interaction of government, industry and academia is shifting, from previous modes of separation or control, into a "triple helix" of overlapping, yet relatively autonomous, spheres with relations among them based upon principles of equality.

\footnotetext{
${ }^{i}$ Machlup, Fritz. 1962. The Production and Distribution of Knowledge in the United States. Princeton: Princeton University Press

ii Bush, Vannevar. 1945 [1960]. Science the Endless Frontier Washington D.C.: The National Science Foundation.

iii see Casas, Rosalba and Matilde Luna eds. 1997. Gobierno, Acadeia y Empressas en Mexico (Mexico City: Plaza y Valdes

${ }^{\text {iv }}$ Etzkowitz, Henry. 2002 MIT and the Rise of Entrepreneurial Science London: Routledge

${ }^{\vee}$ Clemence, Richard. 1951 Esasays on Economic Activities of J.A. Schumpeter. Prot Washington NY: Kennikat Press

${ }^{\text {vi }}$ Etzkowitz, Henry, Magnus Gulbrandsen and Janet Levitt. 2001. Public Venture Capital. $2^{\text {nd }}$ edition New York: Aspen Kluwer

${ }^{v i i}$ Braczyk, Hans Joachim, Philip Cooke and Martin Heidenreich eds. Regional Innovation Systems. London: UCL Press

${ }^{\text {viii }}$ See Etzkowitz, Henry and Loet Leydesdorff eds. 1997. Universities in the Global Knowledge Economy: A Triple Helix of University-Industry-Government Relations. London: Cassell.
}

ix See Bensel, Richard. 1990. Yankee Leviathan: The Origins of Central State Authority in America, 1859-1877 Cambridge: Campridge University Press and Graham, Otis. 1992. Losing Time: The Industrial Policy Debate. Cambridge, MA: Harvard University Press. 